\title{
EARLY TERMINATION COMPENSATION UNDER DEMAND UNCERTAINTY IN PUBLIC-PRIVATE PARTNERSHIP PROJECTS
}

\author{
Jinbo SONG (D) ${ }^{1 *}$, Yanzhu YU (D) ${ }^{1}$, Lulu JIN (D) ${ }^{1}$, Zhuo FENG (iD) ${ }^{1}$ \\ ${ }^{1}$ Faculty of Management and Economics, Dalian University of Technology, Dalian, China
}

Received 22 November 2017; accepted date 29 August 2018

\begin{abstract}
In the early termination of public-private partnership (PPP) projects, compensation is considered a core issue that greatly affects the interests of the government and the private sector. To address the early termination that is frequently caused by government default or voluntary buyback, this paper proposes an ex-ante compensation mechanism using the cumulative probability that a given demand could be realized to determine early termination compensation under demand uncertainty. By splitting the compensation into two parts, the base compensation could be the minimum compensation for the private sector, while the additional compensation is considered a reasonable allocation of future booming demand. The predetermined compensation criterion ensures a smooth transfer of the early terminated project, which not only benefits the government from being overcharged, but also enables the private sector to gain a reasonable compensation for the remaining concession period.
\end{abstract}

Keywords: public-private partnership, early termination, compensation, risk management, Monte Carlo simulation, demand uncertainty.

\section{Introduction}

Public-private partnership (PPP), which is recognized as a mutual commitment between the government and the private sector, has been globally applied with increased value for money to provide public services and infrastructure projects. As an important financing approach for the government to attract private investment, the PPP scheme works effectively to achieve social efficiency, improve service quality and relieve financial pressure from the government (HM Treasury, 2012).

Thus far, a large number of PPP projects have been successfully developed in the field of transportation, infrastructure and social services. However, the experiences of many other projects have not always been positive, an important issue of which is early termination (Valipour et al., 2015). According to the data that are provided by the Private Participation in Infrastructure (PPI) Database of World Bank (2017), 662 out of 16,085 PPP projects were cancelled across the world between 1980 and 2017. Generally, the early termination of PPP projects refers to the ending of an agreement ahead of its scheduled expiry by either party that is involved in the PPP agreement.
In practice, most of the projects, for instance the California Route 91 Express Lanes in the US (Iseki \& Houtman, 2012) and Skye Bridge in the UK (Soomro \& Zhang, 2013), were terminated in the operation period, while a few projects, including the National Physical Laboratory in the UK (National Audit Office, 2006), were terminated in the construction period.

Two representative real-world projects and their outcomes are briefly presented to illustrate the complexity in early-terminated cases. The 91 Express Lanes in California, completed in 1995 with total investment of 134 million US\$ and concession period of 35 years, was delivered as a DBFO-style project. However, the increased congestion on the lanes, growing safety concerns and demands for a new road from the public compelled the government to consider the option of road expansion to add capacity, which violated the "exclusive clause" signed in the contract. As a result, the project was terminated 12 years later with a compensation of 207.5 million US\$ to the concessionaire, much higher than its capital investment of 134 million US\$.

Another failure case is Wutong Mountain Tunnel in China. The BOT contract came into effect in 1997 with

*Corresponding author. E-mail: songjinbo@dlut.edu.cn 
a 30 years concession period. The project, however, constantly suffered from public appeals of cancelling the toll due to frequent congestions and increasing toll level. Failed to reach an agreement on the presented solutions, the government invested a competitive free channel alongside the tunnel, which brought heavy losses to the private sector. The government eventually bought back the project at a fairly low price, while both parties suffered huge losses during the interminable negotiation period.

In the above cases, the private sector relied on the fact that the increasing traffic volume guarantees considerable profit in the remaining concession period, making further attempts from the public sector difficult during the negotiation process. It shows that without ex-ante compensation mechanisms, a lose-lose situation may turn out to be inescapable since neither party would compromise on their interests.

The critical influencing factors for early termination can be summarized as government default factors, private sector default factors and non-default factors (Lee \& Choi, 2015; Martins, Rui, \& Cruz, 2011; Song, Hu, \& Feng, 2017a). Government default mainly refers to the violation of the government's contractual obligations that frustrates the private sector's ability to operate the project or deliver the service (EPEC, 2012). Private sector default mainly refers to the breaches of any of its obligations that affect service performance (Iossa, Spagnolo, \& Vellez, 2007; Zhang \& Xiong, 2015). Non-default factors include force majeure, voluntary buyback by the government, modifications of related laws, changes in the market interest rate and so on (Iossa et al., 2007; Iseki \& Houtman, 2010).

In the event of early termination, valid project assets are generally either transferred to another private sector or to the government to continuously provide services. Therefore, the private sector is entitled to claim compensation from the government in accordance with the following principles (Iossa et al., 2007; Iseki \& Houtman, 2010; U.S. Treasury, 2017): if the early termination is caused by government default or voluntary buyback, the private sector should be compensated for lost profit in the remaining concession period, outstanding debts and additional costs due to the termination (e.g., redundancy payment for employees, sub-contractor breakage cost); if caused by private sector default, part of the initial investment should be compensated, and the government has no obligation to reimburse the equity that was invested for the reason that the senior lenders are insured; if the early termination is caused by reasons of non-default, financial damages should be undertaken by both the government and the private sector, and the latter should be partially compensated for lost profit, outstanding debts and additional costs.

With regard to the risk allocation in PPP projects, a general principle is that the risk should be allocated to the party who can assess and manage it best (Irwin, 2007), based on which a number of risk allocation schemes
(Bing, Akintoye, Edwards, \& Hardcastle, 2005; Hwang, Zhao, \& Gay, 2013; Ke, Wang, Chan, \& Lam, 2010; Ng \& Loosemore, 2007; Roumboutsos \& Anagnostopoulos, 2008) have been developed through questionnaire survey and case studies. Besides, quantitative methods, such as real options (Buyukyoran \& Gundes, 2018; Liu \& Cheah, 2009; Shan, Garvin, \& Kumar, 2010), fuzzy synthetic evaluation model (Xu, Yeung, J. F. Chan, A. P. Chan, Wang, \& Ke, 2010), artificial neural networks model (Jin \& Zhang, 2011), fuzzy analytical hierarchy process model (Khazaeni, Khanzadi, \& Afshar, 2012), principal-agent model (Moore, Boardman, \& Vining, 2017) and bargaining model (Li, X. Wang, \& Y. Wang, 2016; Medda, 2007) were adopted to investigate risk allocation tools for PPP projects.

For the early termination of PPP projects, the determination of appropriate compensation is considered to be a core issue for both the government and the private sector. Practically, a large number of early termination events contribute to the default or initiative buyback by the government. In fact, government decision error and government payment default are considered as the most common reasons for early terminated projects in China (Song, $\mathrm{Hu}$, \& Feng, 2017a). In this situation, the lost profit is recognized as an important compensation claim, the determination of which, however, remains controversial to both parties due to a lack of effective compensation mechanism and inaccurate estimation of demand.

The existing literatures suggest that real-option and NPV method are two most commonly adopted methods in the quantitative analysis of early termination compensation. The real option can capture the valuable sources of flexibility that are either inherent in, or can be built into, corporate assets (Schwartz \& Trigeorgis, 2004; Trigeorgis, 1996). Alonso-Conde, Brown, and Rojo-Suarez (2007) proposed a valuation model to distinguish early termination option from delay payment option and illustrated it by using the Melbourne CityLink project. Huang and Pi (2013) established a real-option valuation model with an extension of the classical Black-Scholes-Merton (BSM) model and discussed the reconciliation between performance bonds and termination rights. Liu, Gao, and Cheah (2017) examined pricing mechanisms for early termination of PPP projects under the scenario of excessively high or excessively low cash flows using real option theory.

While the NPV method is best suited to relatively safe investments and cash cow assets whose value depends primarily on forecasted cash flows (Ng, Xie, Cheung, \& Jefferies, 2007; Xiong, Zhang, \& Chen, 2015; Zhang \& AbouRizk, 2006). Xiong and Zhang (2014) introduced two compensation approaches, specifically compensation based on financial statement and compensation based on discounted value of the future cash flow to address longterm project risks and demand uncertainty. Based on a market value approach, Xiong et al. (2015) developed an early termination compensation model using the discounted cash flow technique with the consideration of the uncertainties of stochastic variables. Song, Fu, and Bagaya 
(2016) proposed an ARIMA model to forecast key influencing factors as dynamic time series data for early termination of highway BOT projects. Besides, game theory was also applied to estimate the compensation for BOT highway projects with incomplete contracts (Song, Jin, Zhao, \& Hu, 2017b).

The current NPV-based compensation approaches are mostly proposed to estimate discounted cash flows in the remaining concession period by developing forecasting techniques such as regression analysis and time series analysis, and determine the compensation only based on the future cash flows before the termination date. Different from these studies, this paper aims at proposing an ex-ante compensation mechanism at the initial stage of a project and facilitating the compensation criterion designs before the early termination occurs. Focusing on the frequent scenario where termination occurs as a result of default or voluntary buyback by the government, a mathematical model is constructed to tackle with the demand uncertainty based on probabilistic analysis, through which the demand risk is fairly allocated between the government and the private sector as they jointly confirmed the demand forecast result and compensation criterion according to the initial demand forecast. Then annual compensation is calculated by adopting NPV method with an overriding principle that the compensation should be neither overcharged for the government nor too meagre for the private sector to cover losses. Meanwhile, detailed provision and specific guidance are designed to deliver equitable result regarding to early termination events.

\section{Research design}

\subsection{Compensation mechanism}

Generally, the demand quantity faces great uncertainty due to the long life cycle of the PPP projects, posing significantly influences on their ultimate profitability (Kokkaew \& Wipulanusat, 2014; Vassallo, Ortega, \& Baeza, 2011). Given that the compensation mechanism is established before a project actually comes into service, demand forecasting for the whole concession period is necessary during the bidding period based on offerings by bidders in their proposals, and it should be evaluated by a government assessment panel (Zhang \& Kumaraswamy, 2001). In practice, the Monte Carlo simulation is recognized as a feasible method to measure uncertainties and forecast critical variables in the project evaluation process (Kwak \& Ingall, 2007). By running the simulation with a large number of iterates, the values of randomly generated target variables will follow a typical statistical distribution, where the statistical description of the parameters, such as the mean value, maximum value and standard deviation, can be obtained as outputs of the simulation (Rezaie, Amalnik, Gereie, Ostadi, \& Shakhseniaee, 2007).

Given the high uncertainty of the actual demand in the remaining concession period, a flexible compensation mechanism is developed by splitting the annual compen- sation into two parts: the base compensation and the additional compensation. The base compensation is determined according to the minimum demand guarantee that could be obtained by the private sector regardless of how the actual demand changes. The additional compensation is recognized as a bonus amount in cases of booming demand in the future.

To demonstrate the compensation mechanism under different annual demands, an analyzing schematics is constructed. As is shown in Figure 1(a), without loss of generality, the probability distribution of the annual demand is assumed to be bell-shaped (Ye \& Tiong, 2003; Zhang \& AbouRizk, 2006), which indicates that the values with a high probability are located in the middle area, and the values with a low probability are located on two sides. The "most-likely" value, which is also recognized as the mean value of the simulation outputs, is determined to be the referential demand. If the actual demand is less than or equal to the referential demand, it is marked as a "pessimistic case" or a "moderate case", respectively; if the actual demand is more than the referential demand, it is then marked as an "optimistic case" to indicate the booming demand.

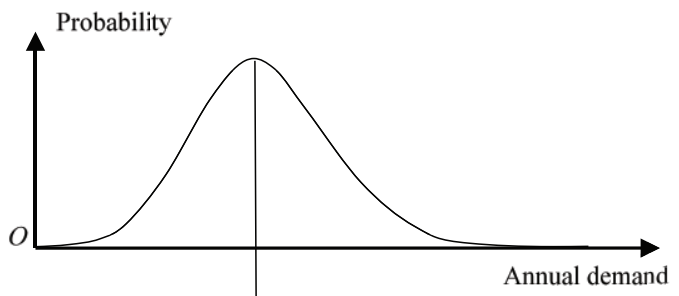

(a)

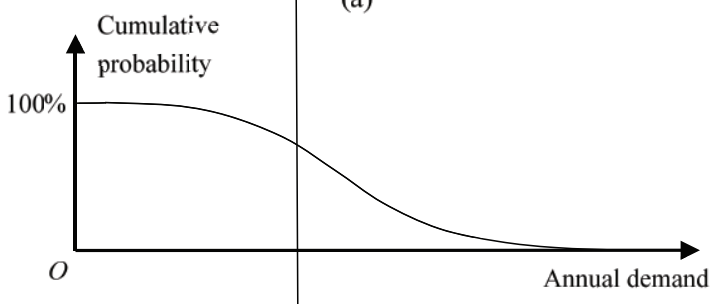

(b)

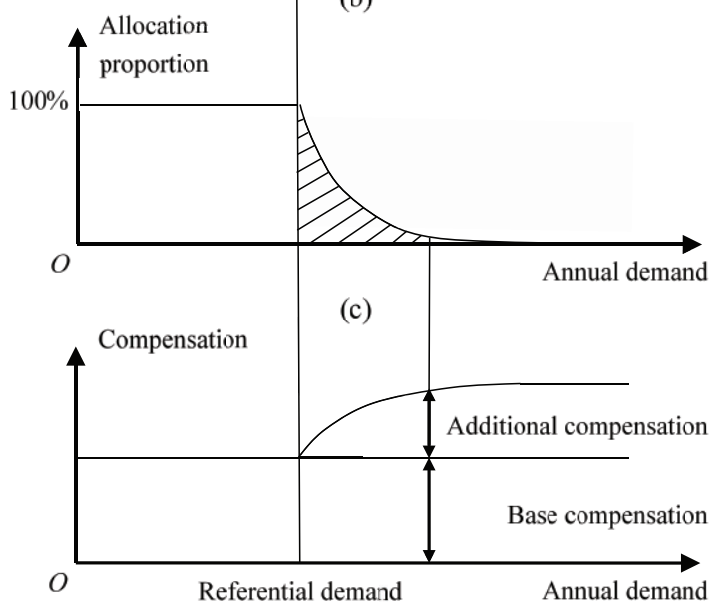

(d)

Figure 1. Compensation analysis under different annual demands 
Accordingly, the cumulative probability curve is illustrated in Figure 1(b), which indicates the probability that a given demand could be practically realized. As the annual demand increases from the minimum to the maximum, the cumulative probability that the annual demand could actually achieve will decline from $100 \%$ to $0 \%$, which means that a low demand level is practically easier to realize then a high demand level. In an optimistic case, the booming demand is realized with a relatively low probability, and the demand above the referential level leads to excessive revenue. In this case, the excessive demand should be allocated fairly due to the private sector's declaration and acknowledgement that the project has a low probability of achieving an excessive demand in the bidding period. Therefore, an allocation proportion for excessive demand is developed based on probabilistic analysis, which indicates the percentage that is accounted for by the additional compensation in the excessive revenue.

As indicated in Figure 1(c), with an initial value of $100 \%$, which denotes that the excessive demand is fully compensated, the allocation proportion sequentially declines to $0 \%$ until the annual demand increases to the maximum value. The additional compensation for the private sector can be expressed as the shaded area, which is enclosed by the curve and horizontal axis with an interval from the referential demand to the actual demand. The allocation of the excessive demand ensures that the additional compensation goes up when the actual demand increases but with a lower growth rate, thus it retains the additional compensation in the private sector at a reasonable level.

The annual compensation, as is illustrated in Figure $1(\mathrm{~d})$, is determined as the sum of the base compensation and the additional compensation. For pessimistic or moderate cases, only the base compensation is counted by the government; for optimistic cases, the base compensation and the additional compensation are both counted. Based on the annual compensation, the total compensation for the remaining concession period is then accumulated as a one-time payment by each of the annual compensation discounting to the termination year.

\subsection{Overall framework}

The overall framework of the compensation mechanism is shown in Figure 2. In the bidding period, an ex-ante compensation mechanism is established by determining a series of annual referential demands based on the Monte Carlo simulation and negotiating the compensation criterion in advance. In the operation period, the actual demand data are acquired, upon which the prediction of the future demand is based. The base compensation and the additional compensation can be calculated by comparing the future demand and the referential demand. If the future demand is more than the referential demand, the private sector is compensated with the base compensation as

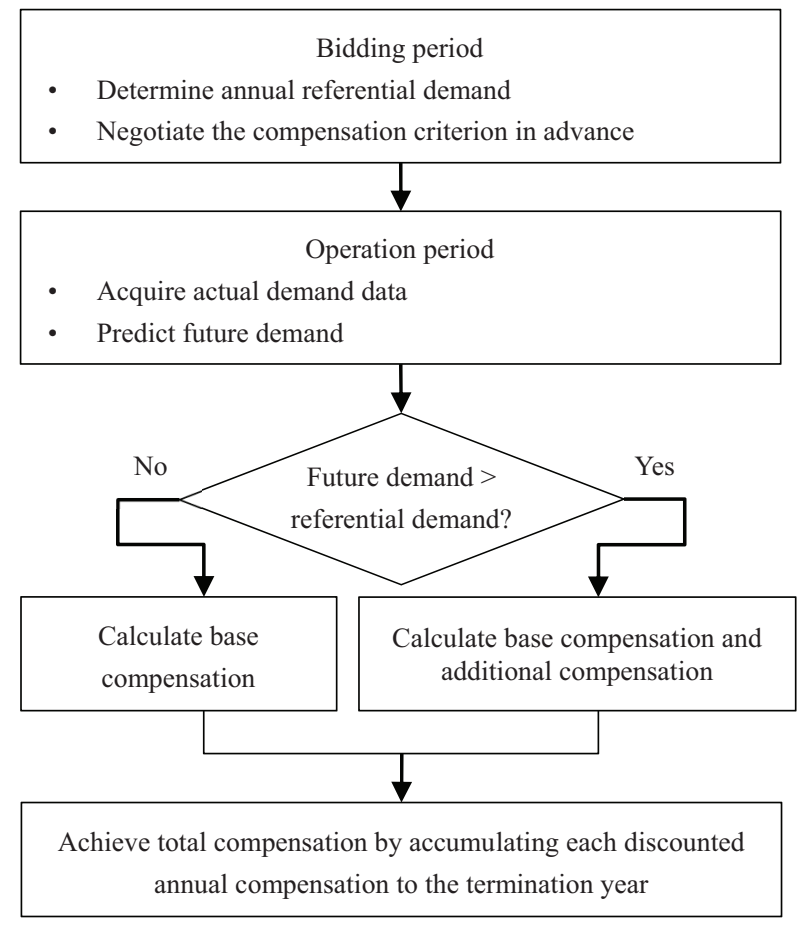

Figure 2. Framework of compensation mechanism

well as the additional compensation; otherwise, only the base compensation is counted. As the annual compensation is determined, the total compensation is obtained by accumulating each of the discounted annual compensation to the termination year.

\section{Compensation model}

\subsection{Assumptions}

Consider a PPP project that is bought back in advance by the government. The planned operation period is $T_{0}$ years, while the government voluntarily terminates the concession agreement at year $T$. The initial construction cost $I_{0}$, which was paid before the operation period began, has been recovered in the operation period. As the compensation model mainly deals with lost profit for the remaining concession period, outstanding debts and other cost items are not discussed. Additionally, the early termination compensation, which is determined on the basis of the above-described compensation mechanism, should be paid by the government at the end of year $T$ as a one-time payment.

\subsection{Demand variables}

\section{Referential demand}

In the bidding period, a series of annual demands within $T_{0}$ years are forecasted as the basis to determine the compensation. Assume that the annual demand increases from an initial value with a specific annual growth rate (Pantelias \& Zhang, 2010): 


$$
Q_{t}=\left\{\begin{array}{cc}
Q_{0}, & t=1 \\
Q_{0} \prod_{j=1}^{t-1}\left(1+\pi_{j}\right), & t \geq 2
\end{array},\right.
$$

where: $Q_{t}=$ annual demand in year $t, t \in\left[1, T_{0}\right] ; Q_{0}=$ initially determined demand in the first year; $\pi_{j}=$ annual growth rate for year $j+1, j \in\left[1, T_{0}-1\right]$.

A Monte Carlo simulation is performed to forecast $Q_{t}$, where the normal distribution $N\left(\mu_{Q}, \sigma_{Q}^{2}\right)$ and $N\left(\mu_{\pi}\right.$, $\left.\sigma_{\pi}^{2}\right)$ are separately assigned to $Q_{0}$ and $\pi_{j}$ to reduce the estimation error (Ye \& Tiong, 2003; Zhang \& AbouRizk, 2006); thus, $Q_{t}$ becomes a stochastic output variable. After running the simulation with a large number of iterates, the probability distribution of $Q_{t}$ forms a bell shape with the highest probability value (most-likely value) occurs at the peak point. The most-likely value, which is denoted as $Q_{t}^{r}$, is recognized as the referential demand in year $t$.

\section{Actual demand}

The annual actual demand in year $t$, which is denoted as $Q_{t}^{a}$, is acquired from the actual operation data within $T$ years. Once $Q_{t}^{a}$ is determined, an offset coefficient that $Q_{t}^{a}$ deviates from $Q_{t}^{r}$, which is denoted as $i_{t}^{a}$, is set by

$$
i_{t}^{a}=\frac{Q_{t}^{a}-Q_{t}^{r}}{Q_{t}^{r}}
$$

Through the collection of $Q_{t}^{a}$, a series of $i_{t}^{a}$ can be obtained, upon which the prediction of the future demand is based.

\section{Predicted demand}

When early termination occurs, the annual predicted demand from $T+1$ to $T_{0}$, which is denoted as $Q_{t}^{p}$, is determined by

$$
Q_{t}^{p}=Q_{t}^{r}\left(1+i_{t}^{p}\right)
$$

where: $i_{t}^{p}=$ predicted offset coefficient that $Q_{t}^{p}$ deviates from $Q_{t}^{r}$. By adopting time series analysis, such as moving averages and regression methods (Adamowski, Fung Chan, Prasher, Ozga-Zielinski, \& Sliusarieva, 2012), the predicted future values are extracted from the previously observed values; therefore, $i_{t}^{p}$ can be predicted based on $i_{t}^{a}$.

\subsection{Estimation of Net Present Value}

The net cash flow (NCF) of a project comes from the difference between cash inflow (CI) and cash outflow (CO):

$$
\mathrm{NCF}_{t}=\mathrm{CI}_{t}-\mathrm{CO}_{t} \text {, }
$$

where: $N C F_{t}=$ annual net cash flow in year $t ; C I_{t}=$ annual cash inflow in year $t ; \mathrm{CO}_{t}=$ annual cash outflow in year $t$, which refers to $I_{0}$ in the construction period and the O\&M cost during the operation period.

For the simplicity, it is assumed that annual cash inflow is calculated as the product of unit price and annual demand (Ng, Xie, Cheung, \& Jefferies, 2007):

$$
C I_{t}=P_{t} Q_{t}^{r}
$$

where: $P_{t}=$ unit price in year $t$.
Prediction of $P_{t}$ can be achieved based on historical data and other related factors (Ye \& Tiong, 2003) with the following equation:

$$
P_{t}= \begin{cases}P_{0}, & t=1 \\ P_{t-1}\left(1+I_{t}-X_{t}+Z_{t}\right), & t \geq 2,\end{cases}
$$

where: $P_{0}$ and $P_{t-1}$ are unit price for the first year and year $t-1$, respectively; $I_{t}=$ inflation rate in year $t ; X_{t}$ and $Z_{t}$ represent the $\mathrm{X}$-factor (productivity offset) and Z-factor (capital recovery factor) in year $t$, respectively.

The O\&M cost, which is directly linked to the scale of initial construction cost and project service time, covers the operation cost, maintenance cost and overhaul cost that comes in subsequent operation years over the project's life cycle. In this study, the O\&M cost is standardized in relation to the initial construction cost and cost escalation rate (Pantelias \& Zhang, 2010), and it is expressed as:

$$
C O_{t}=\varepsilon I_{0}(1+f)^{t-1},
$$

where: $\varepsilon=$ cost coefficient, which indicates the percentage of the first year's O\&M cost counts in $I_{0} ; f=$ cost escalation rate.

During the bidding period, the discounted cash flow (DCF) analysis is commonly adopted by bidders to evaluate the feasibility of the investment opportunity (Luehrman, 1997). With the aim of measuring the profitability of a long-term project using the time value of money, the accumulated net present value (Shen, H. Li, \& Q. M. Li, 2002) is determined as the sum of $I_{0}$ and discounted net cash flows:

$$
N P V_{t}=-I_{0}+\sum_{j=1}^{t} \frac{N C F_{j}}{(1+r)^{j}},
$$

where: $N P V_{t}=$ accumulated net present value generated within $t$ years; $r=$ annual discount rate. The discount rate refers to the interest rate assessed on loans offered to eligible depository institutions such as commercial banks (Zhang \& AbouRizk, 2006). It is also used in DCF analysis to determine the present value of future cash flows.

Within the whole concession period, a positive NPV means that the project is profitable and feasible; otherwise it should be rejected by the bidders. In a least-presentvalue-of-net-revenue (LPVNR) bidding mechanism, the bids are evaluated on the basis of the technical and price proposals, and the winning bid is chosen according to the lowest $N P V_{T_{0}}$ (Engel, Fischer, \& Galetovic, 2001; Nombela \& De Rus, 2004). Therefore the private sector is compelled to conduct the demand forecast cautiously to give a more accurate estimation result.

\subsection{Compensation determination}

\section{Base compensation}

For early terminations that are caused by government default or voluntary buyback, the minimum demand guarantee should be provided in the concession agreement, by which the government guarantees a minimum compensation if the future demand falls below the referential 
demand. The base annul compensation in the remaining concession period, which is determined as the minimum compensation for any of the pessimistic, moderate or optimistic cases, is equal to the profit that could be obtained by the private sector under the referential demand:

$$
B C_{t}=P_{t} Q_{t}^{r}-\varepsilon I_{0}(1+f)^{t-1},
$$

where: $B C_{t}=$ annual base compensation for year $t$, $t \in\left[T+1, T_{0}\right]$.

For a moderate or pessimistic year in which $Q_{t}^{p} \leq Q_{t}^{r}$, the annual compensation equals to the annual base compensation.

\section{Additional compensation}

For an optimistic case in which $Q_{t}^{p}>Q_{t}^{r}$, the annual compensation should be the annual base compensation plus the annual additional compensation. Inspired by the excess revenue sharing mechanism, the excessive demand should be reasonably allocated between the government and the private sector. According to the calculation method of progressive taxation (Bankman \& Griffith, 1987), instead of a fixed value, the allocation proportion should gradually decline as the excessive demand increases to avoid excessive revenue in the private sector and to protect public interests.

Given that $Q_{t}^{p}$ has been predicted from $T+1$ to $T_{0}$, the cumulative probability at the point $Q_{t}^{p}$ is defined as

$$
\left.C P\right|_{Q_{t}>Q_{t}^{p}}=\int_{Q_{t}^{p}}^{Q_{t}^{\max }} f\left(Q_{t}\right) d Q_{t},
$$

where: $f\left(Q_{t}\right)=$ probability density function of $Q_{t} ; Q_{t}^{\max }=$ maximum value of $Q_{t}$, which is obtained from the simulation outputs of $Q_{t} ;\left.C P\right|_{Q_{t}>Q_{t}^{p}}$ can be obtained from the cumulative probability chart of $Q_{t}$ in the look-up table.

The calculation method of the additional compensation is developed based on the progressive method. Assume that the excessive demand interval $\left[Q_{t}^{r}, Q_{t}^{\max }\right]$ is divided into $n$ subintervals $\left[q_{0}, q_{1}\right],\left[q_{1}, q_{2}\right], \ldots,\left[q_{n-1}, q_{n}\right]$ with $Q_{t}^{r}=q_{0}, Q_{t}^{\max }=q_{n}$ and the length of each subinterval, which is defined as the step size, is equal to $\Delta q=$ $\left(Q_{t}^{\max }-Q_{t}^{r}\right) / n$. Note that theoretically $n \rightarrow \infty$ and $\Delta q \rightarrow 0$ so that the additional compensation could be smoothly increased as $Q_{t}^{p}$ grows. In practice, however, the value of $n$ is artificially determined and is relatively low for the reason of simplicity.

For a random step $\delta$, the related subinterval is $\left[q_{\delta-1}\right.$, $\left.q_{\delta}\right]$. The cumulative probability of $Q_{t}$ reaches its lower limit $q_{\delta-1}$, which is denoted as $\left.C P\right|_{Q_{t}>q_{\delta-1}}$, is adopted to determine $k(\delta)$ as the allocation proportion for step $\delta$.

According to the curves of the cumulative probability and the allocation proportion of annual demand in Figure 1(b) and Figure $1(\mathrm{c})$, as $Q_{t}$ increases from $Q_{t}^{r}$ to $Q_{t}^{\max }$, the step $\delta$ for calculating the additional compensation within the subinterval $\left[q_{\delta-1}, q_{\delta}\right]$ moves from 1 to $n ;\left.C P\right|_{Q_{t}>q_{\delta-1}}$ will decline from $\left.C P\right|_{Q_{t}>Q_{t}^{r}}$ to $\left.C P\right|_{Q_{t}>q_{n-1}}$ and $k(\delta)$ will decline from $100 \%$ to $0 \%$. Consider that $n \rightarrow \infty,\left.C P\right|_{Q_{t}>q_{\delta-1}} \rightarrow 0 \%$; therefore, for a random step $\delta$, a one-to-one correspondence be- tween $\left.C P\right|_{Q_{t}>q_{\delta-1}}$ and $k(\delta)$ can be achieved by introducing a linear transformation:

$$
k(\delta)=\left.\xi C P\right|_{Q_{t}>q_{\delta-1}},
$$

where: $\xi$ is a constant. Given that the allocation proportion of the first step is supposed to be $100 \%, 100 \%$ is assigned to $k(1)$. Thus, $\xi$ is determined as $1 /\left.C P\right|_{Q_{t}>Q_{t}^{r}}$ and $k(\delta)$ is rewritten as

$$
k(\delta)=\frac{\left.C P\right|_{Q_{t}>q_{\delta-1}}}{\left.C P\right|_{Q_{t}>Q_{t}^{r}}},
$$

As $Q_{t}^{p}$ is determined, a series of subintervals $\left[q_{0}, q_{1}\right]$, $\left[q_{1}, q_{2}\right], \ldots,\left[q_{h-1}, Q_{t}^{p}\right]$ also can be determined, where $h$ is the last step for $Q_{t}^{p}$ and $q_{h-1}<Q_{t}^{p} \leq q_{h}$. Therefore, the annual additional compensation is

$$
A C_{t}=\sum_{\delta=1}^{h-1} k(\delta) P_{t} \Delta q+k(h) P_{t}\left(Q_{t}^{p}-q_{h-1}\right),
$$

where: $A C_{t}=$ annual additional compensation for year $t$, $t \in\left[T+1, T_{0}\right]$.

\section{Total compensation}

The annual compensation, which is denoted as $T C_{t}$, is the sum of the annual base compensation and the annual additional compensation:

$$
T C_{t}=B C_{t}+A C_{t} \text {, }
$$

The total compensation TC is a one-time payment at the end of year $T$, and it is derived as the sum of the annual compensation discounted to the termination year:

$$
T C=\sum_{t=T+1}^{T_{0}} \frac{T C_{t}}{(1+r)^{t-T}},
$$

To reflect the uncertainty of the interest rate and the inflation rate in the remaining concession period (Zhang \& Abourizk, 2006), here it is assumed that the discount rate $r$ as a stochastic input variable, which follows a normal distribution $N\left(\mu_{p}, \sigma_{r}^{2}\right)$ with a mean value of $\mu_{r}$ and a standard deviation of $\sigma_{r}$. By performing the Monte Carlo simulation, the statistical distribution of TC is finally achieved.

\section{Illustrative example}

An illustrative example of Shuiguan Expressway in China is performed to demonstrate how the compensation mechanism works in the early termination of PPP projects.

Shuiguan Expressway was invested as a BOT project with total investment of 980 million RMB and a concession period of 25 years. The expressway, located in Shenzhen, was opened to public in February 2002. Between March 2009 and July 2011, the project was expanded from 4 lanes to 10 lanes with a cost of 1100 million RMB, making it become the widest expressway in China. As the main artery to city, the traffic volume of Shuiguan Expressway has substantially exceeded the previously designed capacity, leading to frequent congestions in rush hour. It was also pointed out that users suffered from the expensive toll rate, making 
the proposal of cancelling tolls be placed on the agenda for many years. However, the buyback negotiation between the government and the private sector becomes fairly tough. Therefore, the question presented on the early termination of Shuiguan Expressway is how to reach an agreement on a fair and reasonable compensation amount.

For the convenience of discussion, simplified data are adopted from the case to conduct a workable demonstration. Passenger Car Unit (PCU) is primarily adopted to conduct a truer reflection of the highway capacity. Considering the fact that annual traffic demand experienced dramatic changes after the road expansion, it is assumed that road capacity remains the same level in the whole concession period and only the first investment is considered in this numerical example. Based on the data observed in the real project, the toll rate basically remains constant in the whole concession period. The package Oracle Crystal Ball 11.1.2.4 is applied to conduct the Monte Carlo simulation 10,000 times to obtain the probability distribution of the target variables at a $95 \%$ level of confidence. The predicted distributions of stochastic input variables shown in Table 1 are obtained based on expert judgements and actual experience from similar transportation projects. In view of the variance between the expected data and actual data, the values of parameters are adjusted according to the Maximum Likelihood Estimation principle to conduct a relatively persuasive result. These parameters are given below:

- Total construction cost $I_{0}=980$ million RMB;

- The planned and actual operation period are $T_{0}=20$ years and $T=15$ years, respectively;

- Toll rate $P_{t}=10 \mathrm{RMB}, t \in[1,20]$;

- Cost coefficient for the O\&M cost $\varepsilon=3 \%$;
- Cost escalation rate $f=10 \%$;

- The number of steps for calculating the additional compensation $n=5$.

Table 1. Probability distributions of stochastic input variables

\begin{tabular}{|l|l|c|}
\hline \multicolumn{1}{|c|}{ Variable } & \multicolumn{1}{c|}{ Distribution } & Unit \\
\hline$Q_{0}$ & Normal distribution $\left(13,1.3^{2}\right)$ & Million unit \\
\hline$\pi_{j}, j \in[1,4]$ & Normal distribution $\left(8 \%, 1 \%^{2}\right)$ & - \\
\hline$\pi_{j}, j \in[5,9]$ & Normal distribution $\left(10 \%, 1 \%^{2}\right)$ & - \\
\hline$\pi_{j}, j \in[10,14]$ & Normal distribution $\left(5 \%, 1 \%^{2}\right)$ & - \\
\hline$\pi_{j}, j \in[15,19]$ & Normal distribution $\left(3 \%, 1 \%^{2}\right)$ & - \\
\hline$r$ & Normal distribution $\left(12 \%, 1 \%^{2}\right)$ & - \\
\hline
\end{tabular}

A summary of the cost and benefit data within the whole concession period is provided in Table 2. $Q_{t}^{r}$ and $Q_{t}^{\max }$ come from the simulation outputs of $Q_{t} ; \mathrm{CI}_{t}, \mathrm{CO}_{t}$ and $N P V_{t}$ are calculated based on $Q_{t}^{r}$ in the bidding period; $Q_{t}^{a}$ and $i_{t}^{a}$ are obtained from the actual operation data, where the high demands for the first 15 years indicates an optimistic case in the future. From year 16 to year 20 , exponential smoothing method is adopted to forecast $i_{t}^{p}$. In view of the continuous declining trend of $i_{t}^{a}$ from year 8 to year 15, Holt's linear trend method (Holt, 1957) is chosen to forecast $i_{t}^{p}$. The smoothing parameters for the level and trend are 0.76 and 1 respectively, which are obtained through Microsoft Excel Solver's optimization tool by minimizing the sum of squared errors. The forecasting results are shown in Figure 3. $Q_{t}^{p}$ therefore can be calculated based on $i_{t}^{p}$ and $Q_{t}^{r}$.

Table 2. Summary of cost and benefit data

\begin{tabular}{|c|c|c|c|c|c|c|c|}
\hline $\begin{array}{c}\text { Operation } \\
\text { year }\end{array}$ & $\begin{array}{c}Q_{t}^{r} \\
\text { (million unit) }\end{array}$ & $\begin{array}{l}Q_{t}^{\max } \\
\text { (million unit) }\end{array}$ & $\begin{array}{c}C I_{t} \\
\text { (million RMB) }\end{array}$ & $\begin{array}{c}C O_{t} \\
\text { (million RMB) }\end{array}$ & $\begin{array}{c}N P V_{a} \\
\text { (million } \mathrm{RMB} \text { ) }\end{array}$ & $\begin{array}{c}Q_{t}^{a} \text { or } Q_{t *}^{p} \\
\text { (million unit) }\end{array}$ & $i_{t}^{a}$ or $i_{t}^{p}$ \\
\hline 0 & - & - & - & -980.00 & -980.00 & - & - \\
\hline 1 & 13.01 & 16.63 & 130.00 & 29.40 & -890.18 & 8.62 & $-33.74 \%$ \\
\hline 2 & 14.05 & 17.97 & 140.40 & 32.34 & -804.03 & 11.57 & $-17.66 \%$ \\
\hline 3 & 15.17 & 19.44 & 151.63 & 35.57 & -721.43 & 13.04 & $-14.02 \%$ \\
\hline 4 & 16.39 & 21.06 & 163.76 & 39.13 & -642.22 & 16.72 & $2.05 \%$ \\
\hline 5 & 17.70 & 22.84 & 176.86 & 43.04 & -566.29 & 20.16 & $13.88 \%$ \\
\hline 6 & 19.47 & 25.15 & 194.55 & 47.35 & -491.71 & 25.16 & $29.21 \%$ \\
\hline 7 & 21.43 & 27.75 & 214.00 & 52.08 & -418.47 & 28.53 & $33.17 \%$ \\
\hline 8 & 23.58 & 30.68 & 235.41 & 57.29 & -346.53 & 32.14 & $36.34 \%$ \\
\hline 9 & 25.94 & 33.96 & 258.95 & 63.02 & -275.88 & 34.25 & $32.02 \%$ \\
\hline 10 & 28.55 & 37.66 & 284.84 & 69.32 & -206.49 & 36.63 & $28.29 \%$ \\
\hline 11 & 29.98 & 39.55 & 299.08 & 76.26 & -142.43 & 37.28 & $24.34 \%$ \\
\hline 12 & 31.48 & 41.55 & 314.04 & 83.88 & -83.35 & 39.70 & $26.12 \%$ \\
\hline 13 & 33.05 & 43.67 & 329.74 & 92.27 & -28.93 & 41.45 & $25.39 \%$ \\
\hline 14 & 34.71 & 45.92 & 346.23 & 101.50 & 21.14 & 42.08 & $21.23 \%$ \\
\hline 15 & 36.44 & 48.31 & 363.54 & 111.65 & 67.16 & 43.68 & $19.85 \%$ \\
\hline 16 & 37.54 & 49.76 & 374.44 & 122.81 & 108.21 & $43.97^{\star}$ & $17.14 \%^{*}$ \\
\hline 17 & 38.66 & 51.27 & 385.68 & 135.09 & 144.71 & $44.28^{\star}$ & $14.51 \%^{*}$ \\
\hline 18 & 39.82 & 52.83 & 397.25 & 148.60 & 177.04 & $44.56^{\star}$ & $11.89 \%^{*}$ \\
\hline 19 & 41.02 & 54.44 & 409.16 & 163.46 & 205.57 & $44.82^{*}$ & $9.26 \% *$ \\
\hline 20 & 42.25 & 56.12 & 421.44 & 179.81 & 230.62 & $45.05^{\star}$ & $6.63 \%^{\star}$ \\
\hline
\end{tabular}

Note: the symbol of '*) is used to identify $Q_{t}^{p}$ and $i_{t}^{p}$ from $Q_{t}^{a}$ and $i_{t}^{a}$, respectively. 


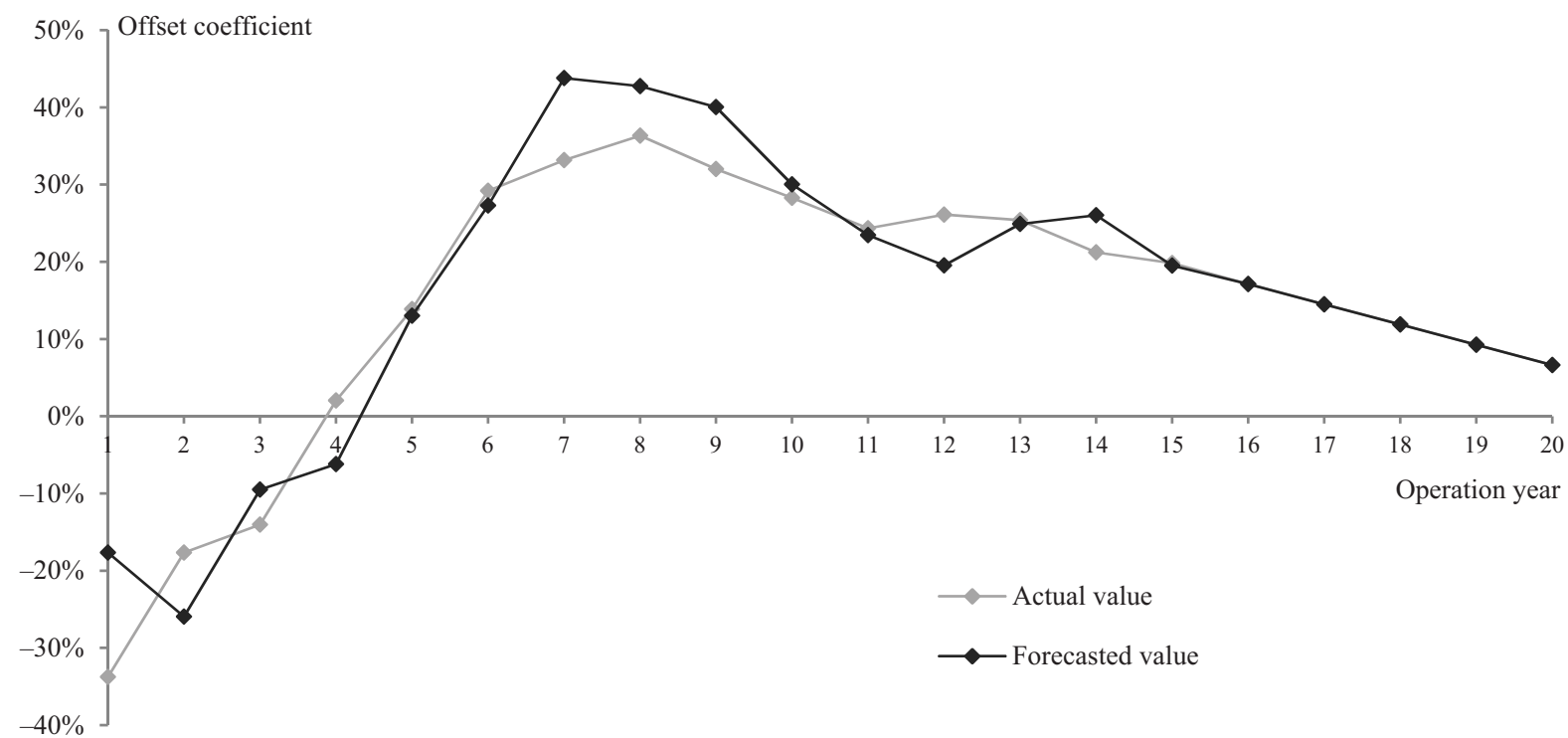

Figure 3. Forecasts of offset coefficient

The calculation of the annual additional compensation for year 16 is shown in Table 3, where $Q_{16}^{p}$ falls into the third subinterval $[42.43,44.87]$ so that the additional compensation in the third step only counts from 42.43 to $Q_{16}^{p}$. Similarly, the $A C_{t}$ for the remaining years are calculated in the same way as that of year 16 . The annual compensation from year 16 to year 20 are listed in Table $4 . B C_{t}$ is the annual profit under the referential demand, which is equal to the difference of $C I_{t}$ and $C O_{t} . T C_{t}$ is the sum of $B C_{t}$ and $A C_{t}$.

Table 3. Calculation of annual additional compensation for year 16

\begin{tabular}{|c|c|c|c|c|}
\hline$\delta$ & $\begin{array}{c}{\left[q_{\delta-1}, q_{\delta}\right]} \\
\text { (million unit) }\end{array}$ & $\left.C P\right|_{Q_{t}>q_{\delta-1}}$ & $k(\delta)$ & $\begin{array}{c}k(\delta) P \Delta q \\
\text { (million } \\
\mathrm{RMB})\end{array}$ \\
\hline 1 & {$[37.54,39.98]$} & $48.81 \%$ & $100.00 \%$ & 24.44 \\
\hline 2 & {$[39.98,42.43]$} & $27.45 \%$ & $56.24 \%$ & 13.75 \\
\hline 3 & {$[42.43,44.87]$} & $12.53 \%$ & $25.67 \%$ & 3.97 \\
\hline 4 & {$[44.87,47.32]$} & $4.73 \%$ & $9.69 \%$ & - \\
\hline 5 & {$[47.32,49.76]$} & $1.25 \%$ & $2.56 \%$ & - \\
\hline Total & - & - & - & 42.16 \\
\hline
\end{tabular}

Table 4. Annual compensation from year 16 to year 20

\begin{tabular}{|c|c|c|c|}
\hline $\begin{array}{c}\text { Operation } \\
\text { year }\end{array}$ & $\begin{array}{c}B C_{t} \\
\text { (million RMB) }\end{array}$ & $\begin{array}{c}A C_{t} \\
\text { (million RMB) }\end{array}$ & $\begin{array}{c}T C_{t} \\
\text { (million RMB) }\end{array}$ \\
\hline 16 & 251.63 & 42.16 & 293.79 \\
\hline 17 & 250.58 & 40.81 & 291.39 \\
\hline 18 & 248.64 & 37.94 & 286.59 \\
\hline 19 & 245.70 & 33.10 & 278.80 \\
\hline 20 & 241.63 & 28.17 & 269.80 \\
\hline
\end{tabular}

By discounting the annual compensation to year 15 , the simulation outputs of the annual discounted compensation and the total compensation are shown in Table 5. The probability distribution and cumulative probability distribution of TC are shown in Figure 4 and Figure 5, respectively. According to central limit theorem, TC tends to follow a normal distribution with mean value of 1029.73 million RMB and standard deviation of 29.92 million RMB. On the basis of the three standard deviations rule, $99.70 \%$ of the 10,000 values generated in the simulation fall into the range of the three standard deviations. Therefore, the mean value 1029.73 million RMB and a bargain range [939.96 million $\mathrm{RMB}, 1119.49$ million $\mathrm{RMB}$ ] are considered to be the reference of a rational total compensation.

Table 5. Simulation outputs of annual discounted compensation and total compensation

\begin{tabular}{|c|c|c|c|c|c|}
\hline $\begin{array}{c}\text { Operation } \\
\text { year }\end{array}$ & $\begin{array}{c}\text { Mean } \\
\text { (million RMB) }\end{array}$ & $\begin{array}{c}\text { Median } \\
\text { (million RMB) }\end{array}$ & $\begin{array}{c}\text { Standard deviation } \\
\text { (million RMB) }\end{array}$ & $\begin{array}{c}\text { Minimum } \\
\text { (million RMB) }\end{array}$ & $\begin{array}{c}\text { Maximum } \\
\text { (million RMB) }\end{array}$ \\
\hline 16 & 262.36 & 262.30 & 2.78 & 252.11 & 274.94 \\
\hline 17 & 232.40 & 232.28 & 4.94 & 214.57 & 255.20 \\
\hline 18 & 204.16 & 203.97 & 6.51 & 181.10 & 234.89 \\
\hline 19 & 177.42 & 177.16 & 7.54 & 151.18 & 213.84 \\
\hline 20 & 153.39 & 153.07 & 8.15 & 924.50 & 193.66 \\
\hline TC & 1029.73 & 1028.78 & 29.92 & & 1172.52 \\
\hline
\end{tabular}




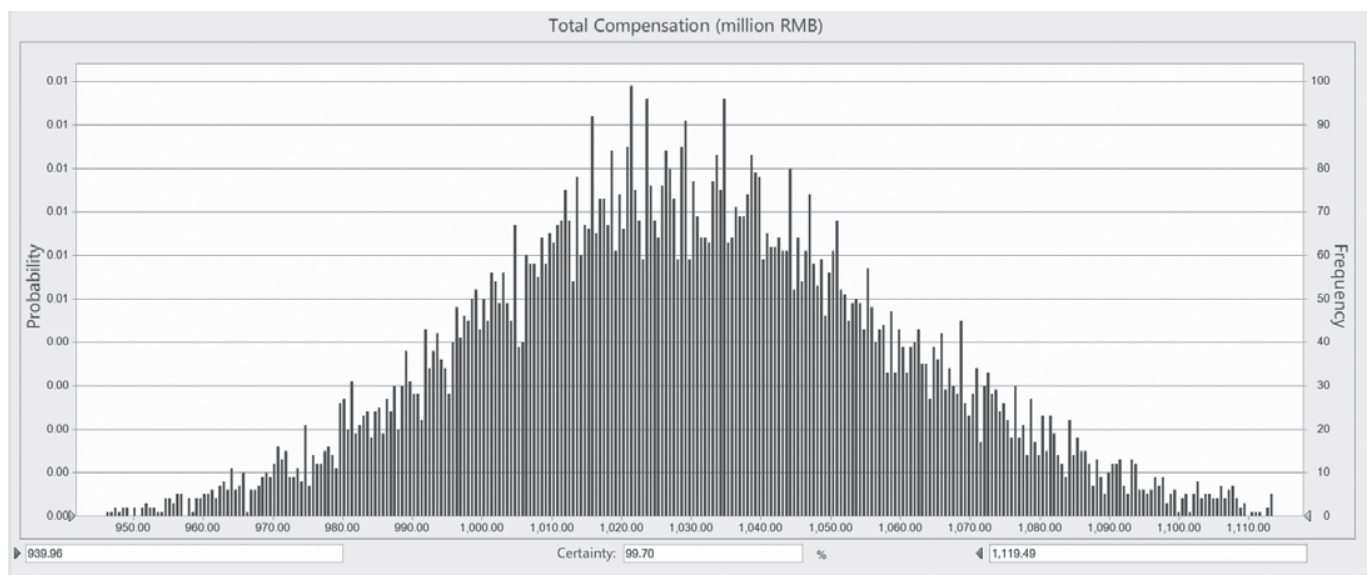

Figure 4. Probability distribution of total compensation

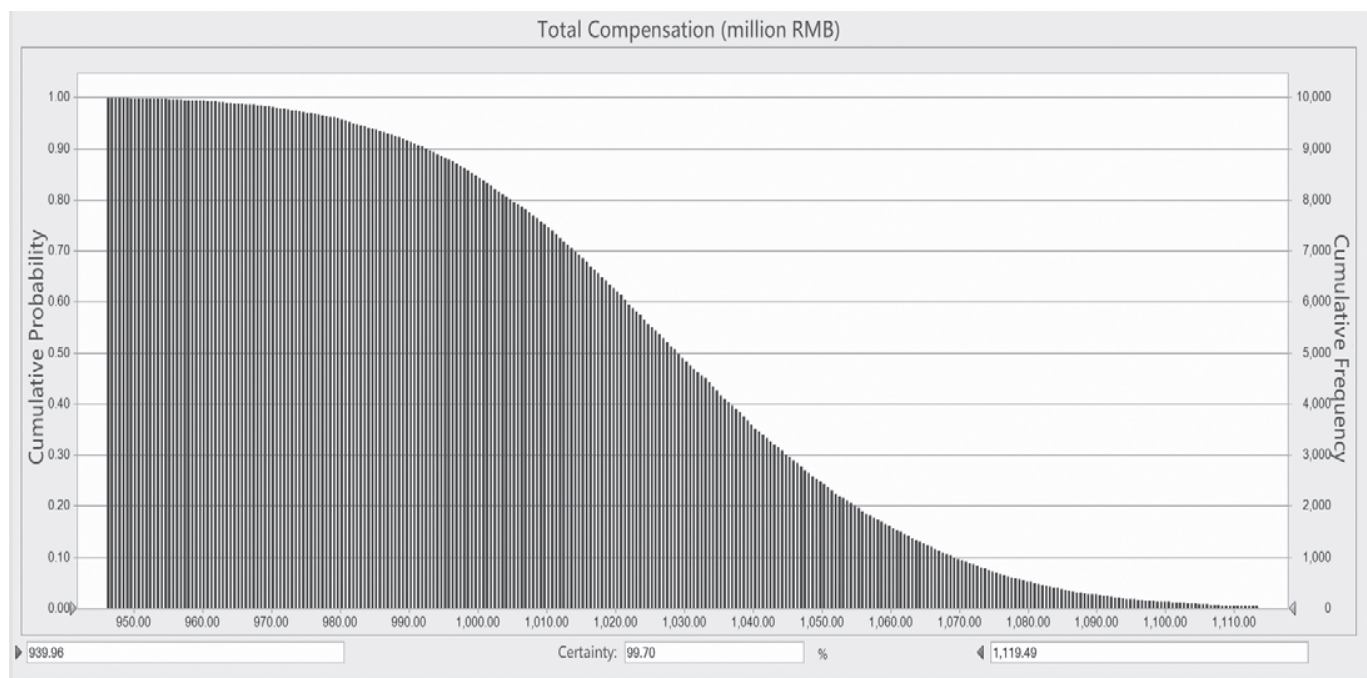

Figure 5. Cumulative probability distribution of total compensation

\section{Discussion}

To further investigate the rationality and effectiveness of the proposed compensation mechanism in terms of early terminated PPP projects, the net present value in three scenarios are illustrated and compared in Figure 6.

All of the curves start from an initial construction cost of 120 million RMB at year 0 . Then the annul NCF is discounted to year 0 and accumulated to the NPV. In the scenario under the referential demand where the NPV is forecasted in the bidding period, the private sector will recover all of its investment in year 14 and obtain 230.62 million RMB as the NPV within 20 years. For a pessimistic or moderate demand, if a PPP project is terminated early, the base compensation in the remaining concession period can be calculated according to the solid curve under the referential demand. For the optimistic demand, the excessive demand should be reasonably allocated, and the additional compensation can be calculated with the proposed mechanism. As is shown in the dashed curve, the private sector will recover all of its investment earlier in year 12 and obtain 252.26 million RMB at the end of year 15. For the remaining 5 years, the annual compensation is supposed to be discounted to year 15 and then summed up as the final compensation. In order to facilitate the analysis, an adjustment is made that the annual compensation is discounted to year 0 and then accumulated in correspondence with the data in the solid curve. In this case, the NPV obtained in the dashed curve will finally reach 440.23 million RMB at the end of year 20, which is $91 \%$ more than the final NPV obtained in the solid curve. The dotted curve, which overlaps the dashed curve on the first 15 years' NPV value, is developed based on the actual data in the first 15 years and the NCF from the predicted demand for the remaining period. In this case, the project is continuously operated by the private sector without allocating the excessive predicted demand, and will finally gain 501.54 million RMB at the end of year 20. This means that without a reasonable allocation of excessive demand, the total profit gained by the private sector will be more than double of the expected profit under referential demand.

From the termination year's perspective, if the annual demand is predicted to be pessimistic in the remaining 


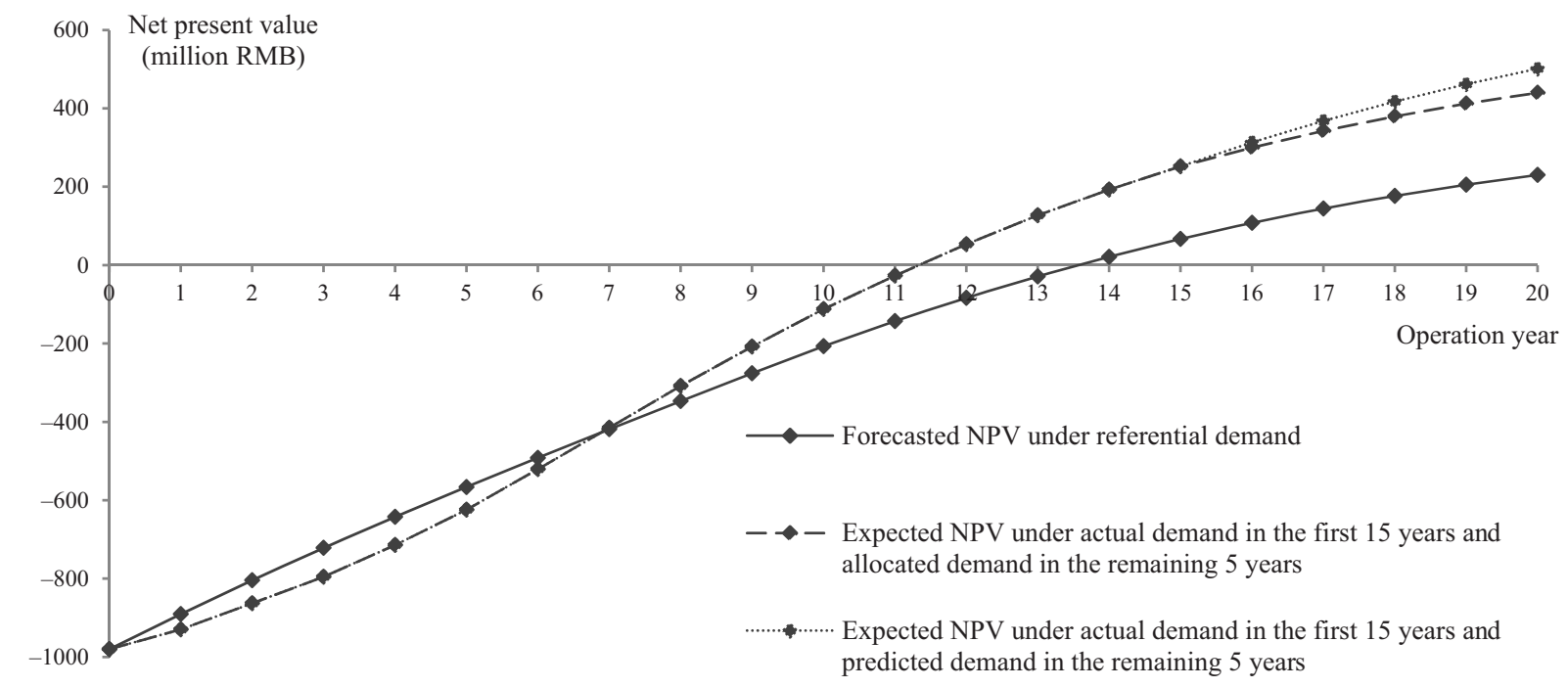

Figure 6. Net present value in three scenarios

concession period, the compensation paid by the government should be the annual referential NCF discounted to year 15 and then summed up, which is $T C_{0}=894.67$ million RMB. As for the optimistic demand case in the illustrative example, the mean value of $T C=1029.73$ million $\mathrm{RMB}$, which is $15 \%$ more than $T C_{0}$. As a comparison, without the compensation mechanism, the private sector would ask for an exorbitant compensation of $T C_{1}=$ 1364.43 million $\mathrm{RMB}$, which is $53 \%$ more than $T C_{0}$.

The result indicates that the private sector is entitled to claim a compensation which is $15 \%$ higher than expected in the bidding period. This should be acceptable for the government who is supposed to be punished for its breaching role in the early termination. Meanwhile, TC turns out to be not too high as $T C_{1}$ to damage the public interests since the excess demand over what the private sector declared in the bidding period has been fairly allocated based on probabilistic analysis. The proposed compensation mechanism not only benefits the government from being overcharged, but also enables the private sector to receive a considerable compensation for the future. It might be argued that the compensation is much lower than the forecasted profit in an optimistic case, but comparably, the private sector would acquire a compensation that is higher than the forecasted profit in a pessimistic case. Consequently, the compensation mechanism works rationally and effectively in the early termination of PPP projects, and would be acceptable to both parties.

\section{Conclusions}

Compensation is the greatest concern in the negotiation process between the government and private sector with regard to the early termination of PPP projects. This paper proposes an ex-ante mechanism to determine the compensation of early termination that is frequently caused by government default or voluntary buyback. In view of the demand uncertainty that appears in the whole concession period, a fair compensation model is developed based on the probabilistic analysis of annual demand, which is conducted through the integration of NPV method and Monte Carlo simulations. The proposed compensation mechanism extends the idea of excess revenue sharing and minimum demand guarantee into the early termination of PPP projects. Rather than using the return on investment to determine the level of government guarantees, this compensation mechanism is proposed based on the cumulative probability that a given demand could be realized to determine early termination compensation under demand uncertainty.

The main contribution of this paper is that demand risk has been fairly allocated between the government and the private sector, who jointly confirmed the compensation criterion and the initial demand forecast as the referential demand using the cumulative probability in the project's bidding period: if the actual demand is higher than the referential demand, the excessive demand should be reasonably allocated; if the actual demand is lower than the referential demand, demand risk should be transferred to the government, who is supposed to provide the compensation at the referential demand level.

This compensation mechanism generates a reasonable compensation for the private sector to recover losses while preventing the government from being overcharged, through which the public interests are protected as well. Moreover, thanks to the predetermined compensation criterion, time-consuming negotiations as well as high expost costs could be hopefully avoided during the contract termination, and a smooth transfer of the early terminated project is more likely to be achieved. For the government, it is beneficial to ease the burden of termination compensation and to avoid excessive revenue in the private sector. For the private sector, it is also acceptable to mitigate risks and to gain reasonable compensation.

Due to the limitation of this research, some cost items including the liabilities, sums payable to subcontractors and insurance cost are not discussed in the model. The 
proposed compensation methodology and simulationbased approach should be compared with other methods, such as real options and game theory, and proven in practice. It is also noted that the responsibility allocation, the residual value of the project, whether the project will be rebid as well as other consequences that are caused by the early termination are worth considering in future research.

\section{Acknowledgements}

The research is supported by the National Natural Science Foundation of China under Grant [number 71734001; 71272091; 71472022 and 71702020]; the Program for Liaoning Innovative Talents in University of China under Grant [number WR2017001]; and the Fundamental Research Funds for the Central Universities of China under Grant [number DUT17ZD208].

\section{Author contributions}

Jinbo Song and Yanzhu Yu conceived the study and were responsible for the research design and methodology. Jinbo Song, Yanzhu Yu and Lulu Jin were responsible for the model development and illustrative example. Lulu Jin and Zhuo Feng developed the data analysis and discussion of the illustrative example.

\section{Disclosure statement}

The authors declare that they have no competing financial, professional, or personal interests from other parties.

\section{References}

Adamowski, J., Fung Chan, H., Prasher, S. O., Ozga-Zielinski, B., \& Sliusarieva, A. (2012). Comparison of multiple linear and nonlinear regression, autoregressive integrated moving average, artificial neural network, and wavelet artificial neural network methods for urban water demand forecasting in Montreal, Canada. Water Resources Research, 48(1), 273-279. https://doi.org/10.1029/2010WR009945

Alonso-Conde, A. B., Brown, C., \& Rojo-Suarez, J. (2007). Public private partnerships: incentives, risk transfer and real options. Review of Financial Economics, 16(4), 335-349. https://doi.org/10.1016/j.rfe.2007.03.002

Bankman, J., \& Griffith, T. (1987). Social welfare and the rate structure: a new look at progressive taxation. California Law Review, 75(6), 1905-1967.

https://www.jstor.org/stable/3480545

Bing, L., Akintoye, A., Edwards, P. J., \& Hardcastle, C. (2005). The allocation of risk in PPP/PFI construction projects in the UK. International Journal of Project Management, 23(1), 2535. https://doi.org/10.1016/j.ijproman.2004.04.006

Buyukyoran, F., \& Gundes, S. (2018). Optimized real optionsbased approach for government guarantees in PPP toll road projects. Construction Management and Economics, 36(4), 203-216. https://doi.org/10.1080/01446193.2017.1347267

Engel, E. M., Fischer, R. D., \& Galetovic, A. (2001). Least-present-value-of-revenue auctions and highway franchising. Journal of Political Economy, 109(5), 993-1020. https://www.jstor.org/stable/10.1086/322832
EPEC. (2012). Termination and force majeure provisions in PPP contracts. Retrieved from http://www.allenovery.com/SiteCollectionDocuments/Termination_Report.pdf

HM Treasury. (2012). Standardisation of PF2 contracts draft. Retrieved from https:/www.gov.uk/government/uploads/ system/uploads/attachment_data/file/207383/infrastructure_ standardisation_of_contracts_051212.PDF

Holt, C. C. (1957). Forecasting seasonal and trends by exponentially weighted moving averages. Office of Naval Research, Research Memorandum No. 52. Reprint in International Journal of Forecasting, 20(1), 5-10.

https://doi.org/10.1016/j.ijforecast.2003.09.015

Huang, Y. L., \& Pi, C. C. (2013). Real-option valuation of buildoperate-transfer infrastructure projects under performance bonding. Journal of Construction Engineering \& Management, 140(5). https://doi.org/10.1061/(ASCE)CO.1943-7862.0000821

Hwang, B. G., Zhao, X., \& Gay, M. J. S. (2013). Public private partnership projects in Singapore: factors, critical risks and preferred risk allocation from the perspective of contractors. International Journal of Project Management, 31(3), 424-433. https://doi.org/10.1016/j.ijproman.2012.08.003

Iossa, E., Spagnolo, G., \& Vellez, M. (2007). Best practices on contract design in public-private partnerships. World Bank, Working Paper. Retrieved from https://library.pppknowledgelab. org/documents/2278

Irwin, T. (2007). Government guarantees: allocating and valuing risk in privately financed infrastructure projects. World Bank Publications. Retrieved from http://hdl.handle.net/10986/6638

Iseki, H., \& Houtman, R. (2010). Examination of recent developments in DBFO public private partnership transportation projects in North America. Online Selected Proceedings of the 12th World Conference on Transportation Research. Retrieved from http://www.wctrs-society.com/wp-content/uploads/abstracts/lisbon/selected/02062.pdf

Iseki, H., \& Houtman, R. (2012). Evaluation of progress in contractual terms: two case studies of recent DBFO PPP projects in North America. Research in Transportation Economics, 36(1), 73-84. https://doi.org/10.1016/j.retrec.2012.03.004

Jin, X. H., \& Zhang, G. (2011). Modelling optimal risk allocation in PPP projects using artificial neural networks. International Journal of Project Management, 29(5), 591-603. https://doi.org/10.1016/j.ijproman.2010.07.011

Ke, Y., Wang, S. Q., Chan, A. P. C., \& Lam, P. T. I. (2010). Preferred risk allocation in China's public-private partnership (PPP) projects. International Journal of Project Management, 28(5), 482-492. https://doi.org/10.1016/j.ijproman.2009.08.007

Khazaeni, G., Khanzadi, M., \& Afshar, A. (2012). Fuzzy adaptive decision making model for selection balanced risk allocation. International Journal of Project Management, 30(4), 511-522. https://doi.org/10.1016/j.ijproman.2011.10.003

Kokkaew, N., \& Wipulanusat, W. (2014). Completion delay risk management: a dynamic risk insurance approach. KSCE Journal of Civil Engineering, 18(6), 1599-1608. https://doi.org/10.1007/s12205-014-1128-4

Kwak, Y. H., \& Ingall, L. (2007). Exploring Monte Carlo simulation applications for project management. Risk Management, 9(1), 44-57. Retrieved from https://www.jstor.org/stable/4143844

Lee, S., \& Choi, J. H. (2015). Wastewater treatment TransferOperate-Transfer (TOT) projects in China: The case of Hefei Wangxiaoying Wastewater treatment TOT project. KSCE Journal of Civil Engineering, 19(4), 831-840. https://doi.org/10.1007/s12205-013-0095-5

Li, Y., Wang, X., \& Wang, Y. (2016). Using bargaining game theory for risk allocation of public-private partnership projects: insights from different alternating offer sequences of participants. 
Journal of Construction Engineering and Management, 143(3). https://doi.org/10.1061/(ASCE)CO.1943-7862.0001249

Liu, J., \& Cheah, C. Y. (2009). Real option application in PPP/PFI project negotiation. Construction Management and Economics, 27(4), 331-342. https://doi.org/10.1080/01446190902807071

Liu, J., Gao, R., \& Cheah, C. Y. J. (2017). Pricing mechanism of early termination of PPP projects based on Real Option Theory. Journal of Management in Engineering, 33(6). https://doi.org/10.1061/(ASCE)ME.1943-5479.0000556

Luehrman, T. A. (1997). What's it worth? A general manager's guide to valuation. Harvard Business Review, 75(4), 132-142. Retrieved from https://hbr.org/1997/05/whats-it-worth-ageneral-managers-guide-to-valuation

Martins, A. C., Rui, C. M., \& Cruz, C. O. (2011). Public-private partnerships for wind power generation: the Portuguese case. Energy Policy, 39(1), 94-104. https://doi.org/10.1016/j.enpol.2010.09.017

Medda, F. (2007). A game theory approach for the allocation of risks in transport public private partnerships. International Journal of Project Management, 25(3), 213-218. https://doi.org/10.1016/j.ijproman.2006.06.003

Moore, M. A., Boardman, A. E., \& Vining, A. R. (2017). Analyzing risk in PPP provision of utility services: a social welfare perspective. Utilities Policy, 48, 210-218. https://doi.org/10.1016/j.jup.2017.08.008

National Audit Office. (2006). The termination of the PFI contract for the National Physical Laboratory. Retrieved from http://webarchive.nationalarchives.gov.uk/20101210142120/ http:/www.official-documents.gov.uk/document/hc0506/ hc10/1044/1044.pdf

Ng, A., \& Loosemore, M. (2007). Risk allocation in the private provision of public infrastructure. International Journal of Project Management, 25(1), 66-76.

https://doi.org/10.1016/j.ijproman.2006.06.005

Ng, S. T., Xie, J., Cheung, Y. K., \& Jefferies, M. (2007). A simulation model for optimizing the concession period of public-private partnerships schemes. International Journal of Project Management, 25(8), 791-798. https://doi.org/10.1016/j.ijproman.2007.05.004

Nombela, G., \& De Rus, G. (2004). Flexible-term contracts for road franchising. Transportation Research Part A Policy \& Practice, 38(3), 163-179. https://doi.org/10.1016/j.tra.2003.10.002

Pantelias, A., \& Zhang, Z. (2010). Methodological framework for evaluation of financial viability of public-private partnerships: Investment risk approach. Journal of Infrastructure Systems, 16(4), 241-250. https://doi.org/10.1061/(ASCE)IS.1943-555X.0000015

Rezaie, K., Amalnik, M. S., Gereie, A., Ostadi, B., \& Shakhseniaee, M. (2007). Using extended Monte Carlo simulation method for the improvement of risk management: consideration of relationships between uncertainties. Applied Mathematics and Computation, 190(2), 1492-1501. https://doi.org/10.1016/j.amc.2007.02.038

Roumboutsos, A., \& Anagnostopoulos, K. P. (2008). Public-private partnership projects in Greece: risk ranking and preferred risk allocation. Construction Management and Economics, 26(7), 751-763. https://doi.org/10.1080/01446190802140086

Schwartz, E. S., \& Trigeorgis, L. (Eds.). (2004). Real options and investment under uncertainty: classical readings and recent contributions. MIT press. Retrieved from https://trove.nla.gov.au/work/7582461

Shan, L., Garvin, M. J., \& Kumar, R. (2010). Collar options to manage revenue risks in real toll public-private partnership transportation projects. Construction Management and Economics, 28(10), 1057-1069. https://doi.org/10.1080/01446193.2010.506645

Shen, L. Y., Li, H., \& Li, Q. M. (2002). Alternative concession model for build operate transfer contract projects. Journal of Construction Engineering \& Management, 128(4), 326-330. https://doi.org/10.1061/(ASCE)0733-9364(2002)128:4(326)
Song, J., Fu, Y., \& Bagaya, O. (2016). Compensation mechanism for early termination of highway BOT projects based on ARIMA model. International Journal of Architecture, Engineering and Construction, 5(1), 53-60.

https://doi.org/10.7492/IJAEC.2016.006

Song, J., Hu, Y., \& Feng, Z. (2017a). Factors influencing early termination of PPP projects in China. Journal of Management in Engineering, 34(1).

https://doi.org/10.1061/(ASCE)ME.1943-5479.0000572

Song, J., Jin, L., Zhao, Y., \& Hu, W. (2017b). Using bargaininggame model to negotiate compensation for the early termination of BOT highway projects. Transportation Research Part A: Policy and Practice, 105, 197-209.

https://doi.org/10.1016/j.tra.2017.06.017

Soomro, M. A., \& Zhang, X. (2013). Roles of private-sector partners in transportation public-private partnership failures. Journal of Management in Engineering, 31(4). https://doi.org/10.1061/(ASCE)ME.1943-5479.0000263

Trigeorgis, L. (1996). Real options: managerial flexibility and strategy in resource allocation. MIT press.

U.S. Treasury. (2017). Compilation of PPP terms and conditions of contract. Retrieved from http://ppp.gov.ie/wp/files/documents/DBFOM_Contract/clause-35.pdf

Valipour, A., Yahaya, N., Noor, N. M., Kildienè, S., Sarvari, H., \& Mardani, A. (2015). A fuzzy analytic network process method for risk prioritization in freeway PPP projects: an Iranian case study. Journal of Civil Engineering and Management, 21(7), 933-947. https://doi.org/10.3846/13923730.2015.1051104

Vassallo, J. M., Ortega, A., \& Baeza, M. D. L. Á. (2011). Impact of the economic recession on toll highway concessions in Spain. Journal of Management in Engineering, 28(4), 398-406. https://doi.org/10.1061/(ASCE)ME.1943-5479.0000108

World Bank. (2017). Private participation in infrastructure database. Retrieved from http://ppi.worldbank.org/customquery

Xiong, W., \& Zhang, X. (2014). Compensation approaches for early termination of PPP projects. Proceedings of the 17th International Symposium on Advancement of Construction Management and Real Estate (pp. 721-729). Springer, Berlin, Heidelberg. http://hdl.handle.net/1783.1/65092

Xiong, W., Zhang, X., \& Chen, H. (2015). Early-termination compensation in public-private partnership projects. Journal of Construction Engineering \& Management, 142(4).

https://doi.org/10.1061/(ASCE)CO.1943-7862.0001084

Xu, Y., Yeung, J. F., Chan, A. P., Chan, D. W., Wang, S. Q., \& Ke, Y. (2010). Developing a risk assessment model for PPP projects in China - a fuzzy synthetic evaluation approach. Automation in Construction, 19(7), 929-943. https://doi.org/10.1016/j.autcon.2010.06.006

Ye, S., \& Tiong, R. L. (2003). Tariff adjustment frameworks for privately financed infrastructure projects. Construction Management and Economics, 21(4), 409-419. https://doi.org/10.1080/0144619032000073550

Zhang, X. Q., \& Xiong, W. (2015). Renegotiation and early-termination in public private partnership. International Journal of Archtecture, Engineering \& Construction, 4(4), 204-213. http://hdl.handle.net/1783.1/78559

Zhang, X., \& AbouRizk, S. M. (2006). Determining a reasonable concession period for private sector provision of public works and service. Canadian Journal of Civil Engineering, 33(5), 622-631. https://doi.org/10.1139/106-010

Zhang, X., \& Kumaraswamy, M. M. (2001). Hong Kong experience in managing BOT projects. Journal of Construction Engineering \& Management, 127(2), 154-162. https://doi.org/10.1061/(ASCE)0733-9364(2001)127:2(154) 